\title{
Biomarkers as prognostic factors in endometrial cancer
}

\author{
Bożena Dobrzycka, Slawomir J. Terlikowski
}

Department of Obstetrics, Gynecology and Obstetrics/Gynecological Care, Medical University of Bialystok

\begin{abstract}
Endometrial cancer is the most common gynecologic malignancy in more developed countries. Approximately $75 \%$ of cases are diagnosed at an early stage with a tumor confined to the uterine corpus. Although most patients are cured by surgery alone, about $15-20 \%$ with no signs of locally advanced or metastatic disease at primary treatment recurs, with limited responsiveness to systemic therapy. The most common basis for determining the risk of recurrent disease has been classification of endometrial cancers into two subtypes. Type I, associated with a good prognosis and endometrioid histology and type II, associated with a poor prognosis and non-endometrioid histology. This review will focus primarily on the molecular biomarkers that have supported the dualistic model of endometrial carcinoma and help determine which patients would benefit from either adjuvant therapy or more aggressive primary treatment.
\end{abstract}

Key words: Endometrial cancer, biomarker, prognosis.

\section{Introduction}

Cancer of the uterus is the seventh most commonly diagnosed cancer that occurs in women, with 189,000 new cases and 45,000 deaths occurring worldwide each year. About $60 \%$ of these occur in more developed countries. The highest incidence rates are in the USA and Canada. The age-adjusted incidence rate in the USA was 23.3 per 100,000 women per year [1]. In other regions, with age-standardized rates in excess of 10 per 100,000 include Europe, Australia and New Zealand, the southern part of South America, and the Pacific Island nations. Low rates occur in Africa (Uganda 3.3 per 100,000) and Asia (China 3.8 per 100,000) [2]. In Poland, the age-adjusted incidence was 13.7 per 100,000 women per year [3].

\section{Etiology and risk factors}

Endometrial cancers are known to be heterogeneous with respect to the expression of biochemical markers, ploidy, degree of differentiation, immunogenicity [4]. The disease is rare before the age of 40 , and $<20 \%$ occur before menopause [5]. Around 5-10\% of endometrial carcinomas have a hereditary basis, with hereditary non-polyposis colorectal cancer being the

Correspondence: B. Dobrzycka, Dept. of Obstetrics, Gynecology and Obstetrics / Gynecological Care, Medical University of Bialystok, Warszawska 15, 15062 Bialystok, Poland; tel.: (+4885) 7488869, fax.: (+4885) 7488860,

e mail: bdobrzycka@gmail.com most common cause [6]. The risk factors relate to hormonal stimulation of the endometrium, such as unopposed estrogen treatment, polycystic ovarian disease and estrogen-producing tumors. Overweight is present in $50 \%$ with endometrial carcinoma, and the risk is linked to disturbances in hormone metabolism related to obesity. Nulliparity is a risk factor for endometrial cancer, and breast cancer patients treated with tamoxifen have a six- to eight-fold increased risk $[4,7]$.

\section{Tumor biology and biomarkers}

The endometrium undergoes structural modification and changes in specialised cells in response to fluctuations of estrogen and progesterone during the menstrual cycle. Long-lasting unopposed estrogen exposure leads to endometrial hyperplasia, which increases the chance of development of type I endometrial cancer. The molecular basis of this process is still not known, since the involvement of only a minority of factors is reproducible [8-11]. The development of endometrial cancer is characterized also by self-sufficiency in growth signals, insensitivity to growth inhibition, apoptosis, angiogenesis, invasion and metastasis [12].

\section{Oncogenes}

Activation of proto-oncogenes is a feature of many malignancies and, not surprisingly, there have been numerous searches for oncogene mutations in endometrial cancer [13]. The proto-oncogenes, HER-2/neu and $E G F R$, both members of the epidermal growth factor 
receptor tyrosine kinase (RTK) family, have an important role in regulating cell growth and differentiation, although it is not clear how a specific signalling pathway corresponds to biological and clinical response [14]. HER-2/neu overexpression is reported in $9-30 \%$ endometrial cancers and has been associated with a metastatic phenotype and poor survival in type II endometrial cancer [15]. KRAS encodes a member protein of the small GTPase superfamily and is involved in signal transduction pathways between cell surface receptors and the nucleus. KRAS mutations have been found in 10-30\% of endometrial carcinomas, predominantly in type I tumors $[8,9,16,17]$. The PIK3CA (p110 $\alpha$ catalytic subunit of $P I 3 K$ ) gene locates on chromosome 3q26.32. Phosphatidylinositol-3-kinase (PI3K) is heterodimeric lipid kinase consisting of a catalytic subunit (p110) and a regulatory subunit (p85) in PI3K/AKT signaling pathway. This pathway is frequently activated in endometrial carcinoma through various genetic alterations and their combinations. Activation of $P I 3 K$ produces the second messenger PIP3 which subsequently activates various down-stream pathways such as AKT $[4,16]$. Mutations in PIK3CA occur in $24-36 \%$ endometrial cancers and are coexisting with PTEN mutations in 14-26\% [18]. Although molecularly targeted therapies have been effective in some cancer types, no targeted therapy is approved for use in endometrial cancer. The recent identification of activating mutations in fibroblast growth factor receptor 2 (FGFR2) in endometrial tumors has generated a new avenue for the development of targeted therapeutic agents. The majority of the mutations identified are identical to germline mutations in FGFR2 and FGFR3 [19]. Mutations that predominantly occur in the type I of endometrial cancer, are mutually exclusive with $K R A S$ mutation $[8,17,20]$.

\section{Tumor suppressor gene defects}

A number of tumor suppressor genes have been shown to contribute to the genesis of endometrial cancers. The genes code for proteins inhibiting tumor growth. When mutated, they become inactive and growth is allowed [21]. Endometrial cancers, from a molecular viewpoint also, resemble proliferative rather than secretory endometrium. PTEN encodes a phosphatase, antagonizing the PI3K/AKT pathway. Decreased PTEN activity causes increased cell proliferation, cell survival and angiogenesis, and is involved in cell adhesion and migration. PTEN can be inactivated by mutations, deletions or promoter hypermethylation. PTEN mutations are reported in $25-83 \%$ of endometrial cancers, more frequently in type I [12,22]. The P53 gene regulates cell cycle, apoptosis and differentiation. P53 mutations have been found in $10-20 \%$ of endometrial carcinomas, while $\mathrm{p} 53$ protein overexpression is present in 15-30\%. Overexpression of p53 is more frequent in type II than type I tumors
[11,37,38]. P53 mutations are considered to be an early event in type II tumors (80-90\%) and a late event for type I tumors (5-10\%) [8,16,22]. Alterations of the CDKN2A ( $p 16$ ) gene have been involved in tumor development in several organs. The $C D K N 2 A$ gene encodes 2 proteins, p16 and ARF. The p16 protein encoded by the CDKN2A gene has been identified as a tumor suppressor. In endometrial carcinoma, loss of protein expression varies from 14 to $74 \%$ in different studies. The underlying mechanism of pl6 inactivation in these tumors is unknown, because mutations, deletions and promoter methylation only occur in 2-6\% [23]. Loss of p16 expression is correlated with $K R A S$ and P53 mutations and is associated with high stage, high grade, and poor survival [13].

\section{Mismatch repair genes (MMR) and microsatellite instability (MSI)}

Microsatellite instability (MSI) is a condition manifested by damaged DNA because of defects in normal DNA repair process. Mammalian mismatch repair $(M M R)$ genes encode for nine proteins (MLH1, MLH3, PMS1,PMS2, MSH2, MSH3, MSH4, MSH5, and MSH6) that interact with each other to form complexes and heterodimers that mediate distinct functions in MMR-related system. This repair process plays a central role in promoting genetic stability by repairing DNA replication errors, inhibiting recombination between non-identical DNA sequences and participating in responses to DNA damage [16,24]. MSI has later been found in $20-30 \%$ of endometrial carcinomas, due to epigenetic inactivation through hypermethylation of the MLHl promoter in most cases. MSI has been reported to be more common in type I than type II cancers $[4,25]$.

\section{DNA ploidy}

Approximately $67 \%$ of type I endometrial carcinomas are diploid, as evaluated by flow cytometry. In contrast, $55 \%$ of the type II carcinomas exhibit nondiploid DNA patterns. Diploid tumors are usually low-grade type I carcinomas with only superficial invasion, and are associated with longer survival than aneuploid carcinomas. Differences in disease-free survival for stage I tumors have been as significant as $94 \%$ for diploid carcinomas versus $64 \%$ for aneuploid carcinomas. Aneuploid tumors are present in $20-35 \%$ of endometrial carcinomas, associated with a high stage, a high grade, type II and deep myometrial invasion [26,27].

\section{Steroid receptors}

The presence of the classic steroid receptors ER $\alpha$ and PR-A have correlated with stage, grade and survival in several studies. Additionally, it is thought that the ER and 
PR status constitutes independent prognostic factors [28]. However, PR, in contrast to ER, is suggested to be a more predictive factor of disease-free survival [29], while some authors have also reported that the presence of steroid receptors does not constitute an independent prognostic factor for endometrial cancer [30]. Therefore, the usefulness of the determination of receptor status in endometrial cancer patients is still controversially discussed.

\section{Angiogenesis}

Angiogenesis has been shown to be a critical aspect of endometrial cancer growth and metastasis [31]. The induction of angiogenesis by a tumor is a controlled process, influenced by angiogenic and angiostatic factors which involves a complex interaction between tumor and endothelial cells. Among many reported angiogenic factors, vascular endothelial growth factor (VEGF) is the most powerful endothelial-cell-specific mitogen that plays a key role in the complicated process of angiogenesis [32]. VEGF strong positive tumors showed a poorer prognosis than VEGF negative tumors. There was a trend towards an association between the strong positive expression of VEGF and 5 -year disease-free survival. These results suggest that VEGF may be an important, clinically relevant, inducer of angiogenesis in type I endometrial cancer [33]. Lymphangiogenic factors have recently been studied in endometrial carcinoma, associating aggressive phenotype with the presence of lymphatic vessel infiltration and high lymphatic vessel density $[34,35]$.

\section{Invasion and metastasis}

Invasion and metastasis are the most insidious and lifethreatening aspects of cancer. Tumors of comparable size and histology can have widely divergent metastatic potential, depending on their genotype and local environmental influences. Metastatic potential is influenced by the local microenvironment, angiogenesis, stroma-tumor interactions, and elaboration of cytokines by the local tissue, and more significantly by its molecular phenotype [36,37]. Specific genetic alterations in cellular adhesion molecules, among them the cadherins and catenins, are important for such tumor-stroma and tumor-vascular interactions [38]. Changes in cadherin expression, also termed the "cadherin switch", have been associated with type II endometrial cancer [39]. Mutations in the $\beta$-catenin and connexin 26 gene lead to high protein expression, and were more common in type I tumors $[40,41]$.

\section{Cancer stem cells and endometrial cancer}

Many features of carcinoma can be explained by the stem cell concept, including clonal origin and heterogeneity of tumors, some associated with transit ampli- fying (TA) cells or progenitors, the mesenchymal influence on cancer behaviour, the local formation of precancerous lesions and the plasticity of tumor cells [42]. Only a small proportion of the tumor actually comprises cancer stem cells about $0.02-1 \%$. Thus, cancer stem cells act as precursor cells that produce the proliferating, more differentiated cancer cells killed by chemotherapy or radiation. Cancer stem cells differ from normal tissue stem cells in that their proliferation is no longer controlled by the neighbouring cells of the stem cell niche [43]. As endometrial stem/progenitors cells become better characterized, their role in endometrial cancer can be assessed [44].

\section{Dualistic model of endometrial carcinoma}

Bokhman first described the pathogenetic classification of two different types of endometrial carcinoma, designated as type I and type II carcinomas, according to the determination of biological properties of the tumor, its clinical course, and the prognosis of the disease [45]. Molecular profiling reveals genetic changes in endometrial cancer that support the dualistic model, in which type I accounts for around $80 \%$, usually of endometrioid type, estrogen-dependent, low grade lesions and type II non-estrogen dependent, poorly differentiated, not associated with estrogenic risk factors and with a poor prognosis. The molecular changes in type I tumors include mutations in PTEN, PIK3CA, $K R A S$, and $\beta$-catenin, along with microsatellite instability, whereas type II are characterized by genetic alterations in P53, HER2/neu, p16, and E-cadherin. In addition, P53 mutations may play an important role in tumorigenesis of type II tumor. These molecular changes can help in the diagnosis of endometrial neoplasms, as well as form the basis of molecular targeted therapy $[8,9,10,16,17]$.

\section{Conclusions}

Newer tumor markers and prognostic indicators are needed to help determine which patients would benefit from either adjuvant treatment or more aggressive primary treatment. Type I cancers are associated with mutations in KRAS, PIK3CA and $\beta$-catenin oncogenes, PTEN tumor suppressor gene and defects in DNA mismatch repair; by contrast, those of type II are associated with mutations in P53 gene, E-cadherin tumor suppressor gene, HER-2/neu and p16 expression and most are nondiploid. The clinical value of these markers for prognostication in a routine diagnostic setting, and predicting response to targeted treatment, remains to be settled.

\section{References}

[1] Horner MJ, Ries LAG, Krapcho M. et al. SEER Cancer Statistics Review, 1975-2006, National Cancer Institute. Bethesda, MD, http://seer.cancer.gov/csr/1975_2006/, based 
on November 2008 SEER data submission, posted to the SEER web site, 2009.

[2] Stewart BW, Kleihues P. World cancer report. Lyon: IARC Press, 2003.

[ 3] Reports based on data of National Cancer Registry. The Maria Sklodowska-Curie memorial Cancer Center, Department of Epidemiology and Cancer Prevetion, National Cancer Registry 2004, http://epid.coi.waw.pl/krn.

[4] Engelsen IB, Akslen LA, Salvesen HB. Biologic markers in endometrial cancer treatment. APMIS. 2009;117(10):693-707.

[ 5] Garg K, Shih K, Barakat R. et al. Endometrial carcinomas in women aged 40 years and younger: tumors associated with loss of DNA mismatch repair proteins comprise a distinct clinicopathologic subset. Am J Surg Pathol. 2009;33(12):1869-1877.

[ 6] Garg K, Soslow RA. Lynch syndrome (hereditary non-polyposis colorectal cancer) and endometrial carcinoma. J Clin Pathol. 2009;62(8):679-684.

[ 7] Fader AN, Arriba LN, Frasure HE. et al. Endometrial cancer and obesity: epidemiology, biomarkers, prevention and survivorship. Gynecol Oncol. 2009;114(1):121-127.

[ 8] Dobrzycka B, Terlikowski SJ, Mazurek A. et al. Circulating free DNA, p53 antibody and mutations of KRAS gene in endometrial cancer. Int J Cancer. 2010;127(3):612-621.

[ 9] Dobrzycka B, Terlikowski SJ, Mazurek A. et al. Mutations of the KRAS oncogene in endometrial hyperplasia and carcinoma. Folia Histochem Cytobiol. 2009;47(1):65-68.

[10] Terlikowski S, Lenczewski A, Famulski W. et al. Patterns of immunohistochemical staining for $\mathrm{p} 53$ expression in hyperplastic endometrium and adenocarcinoma. Folia Histochem Cytobiol. 2001;39 Suppl 2:195-196.

[11] Terlikowski S, Lenczewski A, Famulski W. et al. Proliferative activity in endometrial hyperplasia and adenocarcinoma. Folia Histochem Cytobiol. 2001;39(2):163-164.

[12] Amant F, Moerman P, Neven P. et al. Endometrial cancer. Lancet. 2005;366(9484):491-505.

[13] Liu FS. Molecular carcinogenesis of endometrial cancer. Taiwan J Obstet Gynecol. 2007;46(1):26-32.

[14] Jongen VH, Briët JM, de Jong RA. et al. Aromatase, cyclooxygenase 2, HER-2/neu, and p53 as prognostic factors in endometrioid endometrial cancer. Int $J$ Gynecol Cancer. 2009;19(4):670-676.

[15] Konecny GE, Santos L, Winterhoff B. et al. HER2 gene amplification and EGFR expression in a large cohort of surgically staged patients with nonendometrioid (type II) endometrial cancer. Br J Cancer. 2009;100(1):89-95.

[16] Samarnthai N, Hall K, Yeh IT. Molecular profiling of endometrial malignancies. Obstet Gynecol Int. 2010;2010: 162363. Epub 2010 Mar 28.

[17] Dobrzycka B, Terlikowski SJ, Kowalczuk O. et al. Mutations in the KRAS gene in ovarian tumors. Folia Histochem Cytobiol. 2009;47(2):221-224.

[18] Oda K, Stokoe D, Taketani Y. et al. High frequency of coexistent mutations of PIK3CA and PTEN genes in endometrial carcinoma. Cancer Res. 2005;65(23):10669-10673.

[19] Byron SA, Pollock PM. FGFR2 as a molecular target in endometrial cancer. Future Oncol. 2009;5(1):27-32.

[20] Bansal N, Yendluri V, Wenham RM. The molecular biology of endometrial cancers and the implications for pathogenesis, classification, and targeted therapies. Cancer Control. 2009; $16(1): 8-13$

[21] Vogelstein B, Kinzler KW. Cancer genes and the pathways they control. Nat Med. 2004;10(8):789-799.

[22] Llobet D, Pallares J, Yeramian A. et al. Molecular pathology of endometrial carcinoma: practical aspects from the diagnostic and therapeutic viewpoints. $J$ Clin Pathol. 2009;62(9):777-785.

[23] Salvesen HB, Kumar R, Stefansson I. et al. Low frequency of BRAF and CDKN2A mutations in endometrial cancer. Int $J$ Cancer. 2005;115(6):930-934.
[24] Sulewska A, Niklinska W, Kozlowski M. et al. DNA methylation in states of cell physiology and pathology. Folia Histochem Cytobiol. 2007;45(3):149-158.

[25] Prat J, Gallardo A, Cuatrecasas M. et al. Endometrial carcinoma: pathology and genetics. Pathology. 2007;39(1):72-87.

[26] Mangili G, Montoli S, De Marzi P. et al. The role of DNA ploidy in postoperative management of stage I endometrial cancer. Ann Oncol. 2008;19(7):1278-1283.

[27] Susini T, Amunni G, Molino C. et al. Ten-year results of a prospective study on the prognostic role of ploidy in endometrial carcinoma: dNA aneuploidy identifies high-risk cases among the so-called "low-risk" patients with well and moderately differentiated tumors. Cancer. 2007;109(5):882-890.

[28] Ito K, Utsunomiya H, Yaegashi N. et al. Biological roles of estrogen and progesterone in human endometrial carcinomanew developments in potential endocrine therapy for endometrial cancer. Endocr J. 2007;54(5):667-679.

[29] Kleine WW. Prognostic value of progesterone receptors in endometrial cancer. Cancer Treat Res. 1994;70:93-100.

[30] Sivridis E, Giatromanolaki A, Koukourakis M. et al. Endometrial carcinoma: association of steroid hormone receptor expression with low angiogenesis and bcl-2 expression. Virchows Arch. 2001;438(5):470-477.

[31] Sivridis E. Angiogenesis and endometrial cancer. Anticancer Res. 2001;21(6B):4383-4388.

[32] Krikun G, Schatz F, Lockwood CJ. Endometrial angiogenesis: from physiology to pathology. Ann N Y Acad Sci. 2004; 1034:27-35.

[33] Dobrzycka B, Terlikowski SJ, Kwiatkowski M et al. Prognostic significance of VEGF and its receptors in endometrioid endometrial cancer. Ginekol Pol. 2010;81:422-425.

[34] Donoghue JF, Lederman FL, Susil BJ. et al. Lymphangiogenesis of normal endometrium and endometrial adenocarcinoma. Hum Reprod. 2007;22(6):1705-1713.

[35] Mannelqvist M, Stefansson I, Salvesen HB. et al. Importance of tumour cell invasion in blood and lymphatic vasculature among patients with endometrial carcinoma. Histopathology. 2009;54(2):174-183.

[36] Abal M, Llauradó M, Doll A. et al. Molecular determinants of invasion in endometrial cancer. Clin Transl Oncol. 2007;9(5): 272-277.

[37] Dobrzycka B, Terlikowski SJ, Garbowicz M. et al. Tumor necrosis factor-alpha and its receptors in epithelial ovarian cancer. Folia Histochem Cytobiol. 2009;47(4):609-613.

[38] Hazan RB, Qiao R, Keren R. et al. Cadherin switch in tumor progression. Ann N Y Acad Sci. 2004;1014:155-163.

[39] Stefansson IM, Salvesen HB, Akslen LA. Prognostic impact of alterations in P-cadherin expression and related cell adhesion markers in endometrial cancer. J Clin Oncol. 2004;22(7): 1242-1252.

[40] Fukuchi T, Sakamoto M, Tsuda H. et al. Beta-catenin mutation in carcinoma of the uterine endometrium. Cancer Res. 1998;58(16):3526-3528.

[41] Leśniewicz T, Kanczuga-Koda L, Baltaziak M. et al. Expression of connexin 26 in endometrial adenocarcinoma-analysis of correlations with some anatomoclinical features. Folia Histochem Cytobiol. 2008;46(2):171-176.

[42] Miller SJ, Lavker RM, Sun TT. Interpreting epithelial cancer biology in the context of stem cells: tumor properties and therapeutic implications. Biochim Biophys Acta. 2005;1756(1):25-52.

[43] Polyak K, Hahn WC. Roots and stems: stem cells in cancer. Nat Med. 2006;12(3):296-300.

[44] Gargett CE. Uterine stem cells: what is the evidence? Hum Reprod Update. 2007;13(1):87-101.

[45] Bokhman JV. Two pathogenetic types of endometrial carcinoma. Gynecol Oncol. 1983;15(1):10-17.

Submitted: 4 May, 2010

Accepted after reviews: 30 June 2010 